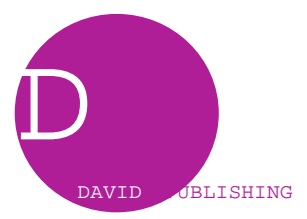

\title{
A Comparative History Partnership From a Historical Institutional Theory View-A Brief Introduction of Three Experiments Beyond Conventional City Planning 1970-1991 in Kotake-Mukaihara District, Tokyo
}

\author{
Chie I. Yamada \\ Public, Place, Plurality Institute, Tokyo, Japan
}

\begin{abstract}
Institutional development and the substantial governance outcomes have continued to be a big theme in Political Science. This paper focuses on partnership practices in public works construction and decision-making cases in city and urban settings (as a socio-political environment). In these settings, the management of policy regarding space and time should conduct on understandings of the various dimensions of institutional settings. We are going to emphasize institution and coordination in the public policy process. So, this paper attempted to describe chronological restrictions that were generated by long-term interactions and institutional transformation's patterns from a historical institutional view. As much as possible, we have analyzed the following micro-institutional experiments, participatory governance (Case I) and public works executions (Cases II and III) to show the institutional development patterns precisely.
\end{abstract}

Keywords: city (urban setting) and policy, institution and coordination, institutional development and resilience, partnership in participatory governance

\section{Introduction}

At first, the author will mention two situations of government reform in the Japanese-style context, in 1960s-70s as follows:

(1) One was proposed by left-wing intellectuals. ${ }^{1}$

(2) The other was conducted as a local government reform by liberal-oriented governors.

In those days, a former governor of Tokyo had started to advocate "participatory governance" in Tokyo.

\section{The Theme in This Paper: Three Stories Regarding Partnership Practices in Public Works Construction and/or Decision-Making}

Currently, this area is around Kotake-mukaihara ${ }^{2}$ Station (Tokyo Metro).

Kotake-Mukaihara District became an example where two public works would be executed, and the next

Chie I. Yamada, Public, Place, Plurality Institute (Tokyo, Japan) is a private organisation to research regarding public policy.

${ }^{1}$ We shall refer the two intellectuals, Tsuji (1972) and Shinohara (1972) in this paper.

${ }^{2}$ Nowadays, the station name is describing in English "Kotake-mukaihara," in, formal. However, each town name is "Kotake” and "Mukaihara" in, formal. 
three projects were tested. We show the location of the Radiation Route of Road 36 in the metropolitan road network (see Figure 1).

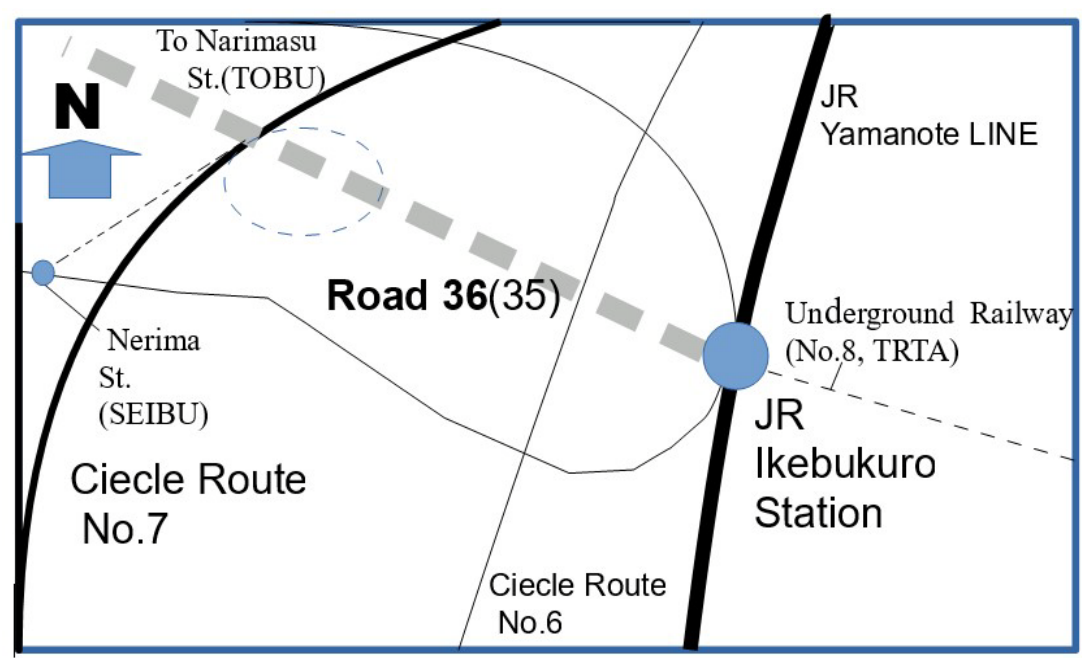

Figure 1. Schematic diagram of the location.

\section{Kotake-muka ihara Station area}

This district was a part of the example area where (1) former Governor of Tokyo, Ryokichi Minobe, who advocated for "democratic city planning", performed a trial of institutionalizing (introduction of the referendum) for the participation-oriented government of Tokyo, in Toshima, Itabashi and Nerima Ward, Tokyo.

This district became two public projects stages as follows:

(2) In the extension of the metro line, it was located at the turning point where two routes crossed (the Tokyo Metro (the Teito Rapid Transit Authority [TRTA] of the day) Yurakucho Line and the Seibu Yūrakuchō Line (additionally, Fukutoshin Line, was opened on June 2008), and it became the stage of the larger-scale new MRT station setting (Kotake-mukaihara Station) in the upper MRT line.

(3) A prefectural road (is a part of the network) was constructed.

Residents' organizations joined both the public works process. The central partnership relations were created across a struggle for a long time.

The residents wanted to minimize the environmental degradation of their quiet residential areas, while the government wanted to execute public work projects. This struggle was a big local issue in Tokyo.

\section{The Structure of This Paper}

This section shows theoretical background and techniques of the observation.

\section{The Theoretical Background}

As a theoretical consideration, we focus on the management of space and time in city and urban settings as policy and political issue.

City (urban setting) and policy. In the context in the research of social movements and urban politics, "more interpenetration between various research traditions (sociology, political science, urban studies, geography, etc.) and worlds of political action (North, South, East, and West) is urgently needed” (Mayer \& Boudreau, 2012, p. 287). "Strategically-organized confrontation", for example, local action and transnational 
struggles (Mayer \& Boudreau, 2012, p. 288) is a big issue related to the people and the meaning.

On the other hand, in the context of urban governance, the scholars argue that "the constraints on institutional capacity and political leadership are considerable” (Pierre \& Peters, 2012, p. 72). Surely, the institutional factors will bring huge impacts to the urban politics and the policy outcomes as follows (Pierre \& Peters, 2012, p. 73):

(1) Local governments are embedded in national (or transnational) institutional and policy frameworks;

(2) The political constraints are linked to nature of policies that the difficulties in addressing many public problems within the confines of individual urban areas;

(3) These economic, institutional, and political constraints on cities define a rather limited scope of local policy choice.

Likewise, "the urban governance perspective is focused on the role of those institutions ${ }^{3}$ in steering and coordinating the local community” (Pierre \& Peters, 2012, p. 74).

We will focus on giving significant consideration regarding institution and coordination as a kind of institutional urban policy study.

Focus on "time" and chronological description-historical institutional view. Pierson (2004) said that focusing on time and observing "institutional development" in the institutional change process, revision, or binding mechanism in the long-term, is an essential matter in political institution studies. Pierson indicated five crucial points in regards to the institutional development are as follows:

(1) Deep equilibria (p. 157);

(2) Menus of institutional change (p. 159);

(3) Institutional coupling (p. 161);

(4) Long-term process of institutional change (p. 164);

(5) From institutional development to policy development (p. 165).

The concept of institutional development is focusing on both the binding or restriction force and the exchanging force (reflecting the functional benefit). These are explained based on the stakeholder's "accumulations" (the results of calculations). In addition, he argued that analysts can expand to policy analysis in the study of political institutions.

For example, Japan and the UK, in central and local governments, disagree that they have witnessed (ideologically based) conflicts "to address a particular societal problem” (Pierre \& Peters, 2012, p. 73). These conflicts situation can be explained by not only by the change-oriented but the maintenance-oriented force. Institutional development refers to both of them, and investigates the combination and the mechanism. Analysts can base their work on this premise.

This report is not aiming at a description of the history, but to analyse institutional development.

\section{The Targets of the Investigation}

We shall narrow it down from these premises and focus on specific targets of the investigation.

Focusing on the core relationship. At first, we focused on "the core relationships"; it includes "reputation, trust, and reciprocity as they affect cooperation” (Ostrom, 2007, pp. 200-202).

These are because the existence of the core relationship affect "To identify potentially deep equilibria"

\footnotetext{
3 They pointed to the institutional importance of the jurisdictional responsibility, as “accountability, transparency" (Pierre \& Peters, 2012, p. 84), etc., or “some normative benchmarks” (Pierre \& Peters, 2012).
} 
(Pierson, 2004, p. 160) and these may cause "long-term process of institutional change” (p. 164).

Ostrom's (2005, p. 154) statement model included that potentially cumulative patterns that can affect individual expectations. The micro and actor-based institutional situations are described as an analogy of "game" as follows:

(1) The shared strategies game adds a set of shared strategies.

(2) The norms game adds a cooperation norm to the base situation. Stakeholders share a "norm". It may include the shared criteria or understandings.

(3) The rules game adds a cooperating rule, a monitoring norm, and a sanctioning norm to the base Prisoner's dilemma game.

For example, the author can say that the stakeholders share the "rules game" in the third settings.

These situation definitions are helpful to create a precise analysis regarding (negotiation) interaction situations.

We shall describe negotiation situations using the three game situations, and the investigation of existence of the "regularity oriented actions". The reason for doing this is that the "regularity" action tendency is necessary to join the "game".

In addition, Ostrom predicted that the third game setting, the rules game, would be effective to conserve the best condition of resources, as space "commons". ${ }^{4}$ As a policy outcome, Ostrom's theory may show similar tendencies in cities and/or the urban environment.

We will prove that the interaction-based institutions with shared understandings (these including strategies, norms, and rules) improve the relationship in the long-term when it comes to the core relationship. ${ }^{5}$

Besides, we would like to show an expectation of institutional change or continuity based on Pierson's compromise.

Institutional stability and/or mobility as "cost calculation" and the institutional outcome. Pierson's compromise, regarding long-term institutional developments and/or constraints, these could explain the stakeholders' calculation. The institutional continuity may depend on, not only positive intentions (interests or desires), but also negative expectations (for example, rising cost calculation).

When we apply the compromise between the institutional settings and the individual expectations, we can find "a combination of settings" as follows (include the following two choices and two items):

(1) The capability of being mobile is high $(=a)$, or low $(=b)$.

(2) The capability of being stable is low $(=1)$, or high $(=2)$.

The brief explanation of the combination of settings is as follows. The logical combination includes a1 (Stakeholder's benefit calculation is high and the cost is low, hence weakest binding setting), a2, b1, and b2 (Stakeholder's cost calculation is high and the benefit is low, hence strongest binding setting).

By using these distinctions, we will show the expectation of institutional change or continuity. Then, we shall compare the substantial results of each case.

Trends of policy outputs. Pierson (2004) suggested the importance to think of major public policies as important institutions. So, we tried to deal with picking up the diversity of the issues and doing additional

\footnotetext{
${ }^{4}$ Ostrom (2005) pointed the relationship between the game (micro-institutional) settings and the outcome of the CPRs conservation or degradation.

${ }^{5}$ Another type of relationship in “coproduction” is obviously different. In the context of "coproduction”, only people (consumers) can be involved, because "the active involvement of the consumer is a requisite input for the production of a high quality good or service” (McGinnis, 1999, p. 7).
} 
comparative descriptions of policy outcomes in this case study, from timing, typology, and institutional settings. The Methods and Materials

In the following part, we will give a brief introduction, regarding the methods and materials used in this paper.

The process tracing and the complete enumeration of negotiation interactions. We adopted two methodologies to describe the history of the partnership in the long-term.

(1) Process tracing. The description of the matter's sequential pathway and/or decision-making process related to the transformation from causal settings to effective settings (Evera, 1997/2009, p. 66). Besides, we made the research design based on "method of difference" using positive and negative examples. ${ }^{6}$

(2) Causal-process observation rather than data-set observation, as follows: The approach needed to control the variables by the number of observations that mean "adding 'piece of data"” (Brady, Collier, \& Seawright, 2004, p. 252). With this method, it is always possible to increase the number of qualitative observations as long as these follow a logical consistency. Opposite, the latter control the variable by the number of examples, and statistics is the basic logic, so sometimes observing with leaving out unsuitable data for statistical analysis (Brady et al., 2004, p. 252).

We worked on the events cited in our study by focusing on negotiations interactions policy process, as a kind of cause and effect process observation (process tracing). These procedures were applied to all available data, and the detailed interaction negotiations were analyzed (the complete enumeration of negotiation interactions).

Using an abundance of records. There are the theoretical backgrounds for more appropriate ways "to analyze practices”.

Wagenaar and Cook (2003) pointed out the importance of analyzing the origins of "value", and they discuss the meaning of practice analysis. Compared with the rational approach that the lack of analysis of value origination (with the command and control stance), practice-oriented approach attempt to understand "local actors' intimate knowledge of the complexities of situations” (Wagenaar \& Cook, 2003, p. 171).

As a result, the analyst can find policy origination (and the policy is sustained by the practices) and origins of value as follows: "Practice ... involves people’s values, emotions, and sense of identity" (Wagenaar \& Cook, 2003, p. 171).

This study will add different vocabulary by the practice-oriented policy analysis (Wagenaar \& Cook, 2003, p. 170) using an abundance of records. ${ }^{7}$

Summary of this part. Lastly, the author summarizes this part as follows:

(1) We shall try to compare partnership histories to the patterns of interactions, or core relationship;

(2) We are going to focus on the long-term "process";

(3) We shall follow appropriate ways of analysis to focus on "practice".

\section{A Brief Introduction of Three-Experiment Story: Beyond Conventional City Planning ${ }^{8}$}

The next section concerns three cases and they are as follows:

(1) Case I is about the participatory governance and related affairs, and these will show the former governor

\footnotetext{
${ }^{6}$ I settle Case I the negative one. And then, Case II and III are both infrastructure project, however, the facility (and authority in charge) is the difference. I will consider regarding these differences.

7 For example, see Appendix of this paper.

${ }^{8}$ Please refer to the detailed negotiation interactions of each case in Yamada (2018, June, pp.7-20, 26-40).
} 
of Tokyo’s advocacy (1970-1975).

(2) Case II is about the public works execution (1), and it will show "a railway work process in Kotake-Mukaihara District” (1975-1985).

(3) Case III is about the public works execution (2), and it will show "a roadwork process in Kotake-Mukaihara District” (1979-1991)

There is the introduction of this city planning in a document collections of the Tokyo Metropolitan Government Bureau of Citizens and Cultural Affairs (1982) as follows:

(1) In 1927, the road that ran the same course as Road 36 (etc.), there was a road construction plan of a 15-meter wide road.

(2) And, the plans were changed twice after 1927. In 1946 and 1966, two decades between the two the road planners continued to change the road width, routes, and other traffic conditions. By 1966, the road plan has evolved into a main road plan to be included in the metropolitan road network. "The road commonly known as '36 Doro (Road 36)'” can connect with emission route 35, supporting route 78 which will become the emission highway that links the Omiya bypass to the Ikebukuro Station west exit.

(3) Under the Road 36 plan, there was a plan to excavate subway tunnels for MRTs linking Narimasu, Nerima, and Ginza. Constructions for the MRT underground railway No.8's Ikebukuro to Ginza 1 Chome track was authorized by the government in 1970 .

(4) The authorities (government and/or the planning division) intended to construct the road and the MRT underground railway simultaneously.

Road 36 Issue "generated the issue with Road 35 • 36" (pp. 1-4).

We can understand the complicated history of the infrastructure projects. This road had four decades of history.

Due to the vast amount of material, we will give a short history of each case in this paper.

\section{Case I: The Referendum Planning of Tokyo and the Participatory Governance 1970-1975}

Road 36 Issue began with the Tokyo Metropolitan Governments' released plan that the MRT underground railway works and Road 36 roadwork construct simultaneously. The stakeholder made a lot of petitions.

Receiving it, the former Governor Ryokichi Minobe promoted his Advocacy "democracy-like governance with Metropolitan citizens" and told the citizens that the government needs the strong support of the metropolitan citizens. ${ }^{9}$

At first, he held Town Meetings. A lot of residents' or residents groups joined the governments' meetings. However, they could not reach a consensus.

And 2nd, he released a plan for a referendum, and the 36 Research Committee established. ${ }^{10}$

\footnotetext{
9 Based on the Tokyo Metropolitan Government Bureau of Citizens and Cultural Affairs (1982, p. 301).

${ }^{10}$ In "Hosha 36 Go Doro no Jumin Tohyo ni Kansuru Chosa Kai Secchi Yoko (official guideline for the establishment of the committee relating to conducting a referendum for Road 36)," the following statement was stipulated. (1) Purpose: To conduct investigations to contribute to conducting the referendum, and purposely to find out public opinions, etc. (2) Organization: The Commissioned members include eight people (people of experience or academic standing) and 4people (residents' representative in Itabashi and Nerima ward, whom the chief of ward recommended). (3) Themes of the research: (1) The method of the referendum relating to Road 36 Project; (2) Any other necessary matter. (4) Meeting: The meetings of The 36 Research Committee shall be called and sponsored by the Governor of Tokyo. (5) The office works: The office work relating to the 36 Research Committee is dealt with Tomin-Shitu (Citizens-room). (6) Application: This guideline applies it from December 22, 1972. (Tokyo Metropolitan Government Bureau of Citizens and Cultural Affairs, 1982, p. 95)
} 
The body showed the basic principle of the road construction ${ }^{11}$ during the early stages as follows:

(1) Environmental assessment;

(2) Freedom of information (accessibility of information);

(3) Citizen participation.

The 36 Research Committee conducted researches (environmental assessments, a public opinion poll, etc.) and managed public relations activities (making a participation opportunity, putting into accessibility of information through release mini-communication paper ${ }^{12}$, etc.), and reached the last stage, i.e., submitting their report dated March 12, 1975 to the current Governor, Mr. Minobe. That is to say, Mr. Minobe hoped to embed these rules into the conventional city planning procedure.

Lastly, we mention the result of the experiment.

At first, the government made a decision-making that they prioritize MRT underground railway works (not road-works).

And second, regarding residents, only four residents (or groups) involved the governments' committee. Other residents (or groups) became public relation's targets.

Lastly, an excluded non-committee members group was formed, so they can express their opposing opinions on the activities of the government's committee. ${ }^{13}$ These people are the ones most affected by the actions of the committee and the former governor.

\section{Case II: The Execution of the MRT Underground Railway Works, 1975-1985}

The government decided to prioritize the MRT underground railway work (1975). Teito Rapid Transit Authority (TRTA) started information sessions for residents in July 1976, by residents' demand.

Received it, The Committee for Quality Control of The MRT underground railway No.8 and No.13 construction (The 8.13 Residents' Committee) ${ }^{14}$ was established in 1976. They made basic demands that the TRTA should sign a series of contracts; otherwise they would not agree to accept the investigations, moreover asked for the return. "If TRTA promise, we will approve only this railway plan and we will cooperate". ${ }^{15}$

The formal (and hard) negotiation started (1976/10/22). After repeated negotiation, Memorandum (1977/03/18) was established $\{11\} .{ }^{16}$ After that land investigation was approved.

Through negotiation interactions, crucial rules were established in the cooperation agreement (1978) between TRTA and the organization. ${ }^{17}$

\footnotetext{
11 Based on "Introduction of Interim Report (1973)" in Machi to Doro (City and Road), No.1 (1973/09/15).

12 The Tokyo Metropolitan Government's newsletter, Machi to Doro (City and Road) No.1 (1973/09/15)-No.11 (1975/09/20) were published regularly.

13 They distributed their newsletters widely among residents. For example, in an article titled "The Public Opinion Poll was settled", they especially captured the poll results that indicated that 70 percent of the citizens wanted the government to hold the resident's opinion in high regard. We can find newsletters: Oshirase (Information), No.1 (1970/07/28)-No.19 (1976/07/02) (Tokyo: The $35 \cdot 36$ Residents' Meeting).

${ }^{14}$ In their organization, the $90 \%$ stakeholders would join through the chance to get negotiation between TRTA (Document for a press release, dated 1980/11/15 by The 35 - 36 Residents Meetings, liaisons).

15 They argued TRTA had: (1) A technological problem; (2) An attitude to prioritize earning a profit; (3) Necessity to change disregard attitude; and (4) The necessity to show an introspective posture through the negotiation process, also. ("Renmei Shuisho" dated 1976/09/16 (The prospectus))

${ }^{16}$ We referred following newsletters: Kaiho (The Measures' information), No.1 (1976/09/03)-No.53 (1985/01/08), (Tokyo: The 8.13 Residents' committee) in this section. I show as follows: \{number\}.

17 The number of negotiation were 107 times (Document for a press release dated 1980/11/15) or the number of formal meetings were 55 (Written request dated 1978/10/24).
} 
Through these negotiation interactions, the 8.13 Residents' Committee obtained crucial rules. ${ }^{18}$ After these contracts were established, TRTA started the construction procedure. Through the process, the stakeholder's consultation made additional design item dealing, as negotiations. ${ }^{19}$ After that, some issues (The MRT ground railway’s new station naming issue) repetition harmed projects' efficiency and stakeholders' trustworthy.

The first railway (the part of Tokyo Metro Yurakucho Line: Ikebukuro-Kotake-mukaihara-Eidan narimasu) was opened on June 1983.

Lastly, we show the results of the negotiation. By repeated negotiation interaction, the residents involved stakeholders. The residents asked to be included in the execution process to modify the rail works' construction plan, in order to ensure a livable environment. They had their own principle (livable, ecological-oriented, basic policy) regarding urban problems. Moreover, they hoped democratic-oriented problem solutions.

\section{Case III: The Execution of Road 36 Works, 1979-1991}

The Government of Tokyo started to find out the residents' opinions in 1979. Informal negotiation meetings were held repeatedly.

Receiving it, the residents' group established The Committee for Quality Control of Road 36 construction (The 36 Residents' Committee) in 1980. They submitted Requisition (1980) as crucial stem items regarding the roadwork. $^{20}$

The former Governor Shunichi Suzuki received it, responded to the requisition by sending an official written response (1980).

The Government and the Residents' Committee signed their Film commitment (on July 1981) before signing of “Agreement”. In this commitment, crucial items (or rules) set. ${ }^{21}$

After the establishment of Mutual agreement (September 1981), the roadwork advanced through negotiations in the 36 consultation. Through the negotiation process, they added policies. For example, the environmental assessment instruction manual that was made by the residents' Committee and the Government of Tokyo was included $\{6,7,8,9$, and 10$\} .{ }^{22}$

Besides, a sidewalk "Four Seasons Street” was constructed at first in $1985\{15\}$.

Only the main roadwork construction remained at last. It included critical problems. So, the residents' desired keeping on writing precise documentation of any events. After that, new Agreement (1987/03/20) and Mutual agreement (1987/03/20) were signed in 1987.

Lastly, we mention the results of the negotiation.

Stakeholders endeavored to maintain not only the rules but also a strong relationship and partnership-philosophy. In the latest agreement, they recorded what had happened in the public document in

\footnotetext{
18 These include, (1) The insurance rule; (2) The starting rule; (3) The consultation rule; (4) The consensus making rule; and (5) The suspending rule. (The cooperation agreement dated 1978/07/07)

19 See Yamada (2018, June, pp.15-16).

20 These include, (1) The road structure and function (anti-pollution, environmental consideration), (2) Site compensation issues, (3) Construction management issues, (4) Environmental impact assessments, (5) House damage control issue, (6) Negotiation procedures, (7) Consensus making of road service opening duration.

21 These include, (1) The consultation rule (continuing post road service), (2) The responsibility range (necessary road planning items, construction management planning), (3) A provision of dealing in doubt to pursue the project, (4) The consensus making rule about road service beginning duration.

${ }^{22}$ We referred following newsletters: 36 Renmei News (The Committee’s News), No.1 (1980/11/04)-No.20 (1987/06/15), (Tokyo: The 36 Residents' Committee) in this section. I show as follows: \{number\}.
} 
1987, and had continued to relate to managing the road.

\section{A Comparative Partnership in Chronological Order by Micro (Interaction-Oriented) Institutional View}

Before we move on, we will mention the constraints related to urban politics (Basically, these based on Section 1) as follows:

(1) Local government is constrained by the central government.

(2) Authorized city planning may be had strong resilience.

(3) In Japanese, local governance the setting may be as follows:

a. The local governments' autonomy has not been able to be practiced for a long time (Tsuji, 1972, p. 146).

b. Japanese modern society (in the 1970s) may have been authoritarian settings (Shinohara, 1972, p. 112).

We shall see whether these urban political constraints will or will not relate to the results of negotiation interactions, in these cases, indirectly.

\section{The Investigation of the Interactions in Public Works}

We will try to compare regarding partnership histories and the patterns of interactions, in other words, core relationships.

In conformity following settings, we consider the details of each negotiation interaction as typical core relationship building processes, to be questioned, as follows.

Q1. How were the negotiation patterns generated?

We shall observe patterns based on Ostrom's statement models, strategies, norms, and rules game.

Q2. Whether or not the core relationship established regarding "reputation, trust, and reciprocity" (Ostrom 2007)?

Q3. How were institutional developments patterns generated?

(Descriptions of micro institutional development (ID): As the long-term “interaction negotiation” patterns)

Q4 How were policy outcome patterns generated?

(The tendency of the policy transformation)

Q5. Was making partnership (core relationship) practice accomplished or not?

(Comparative Evaluation in Conclusion)

\section{Summary: The Investigation of the Interactions in Public Works}

We summarized the result of Q1, Q2, and Q3.

In Case I, exclude only four resident group committee members, almost all citizens became just the public relation target. The setting was "no (negotiation interaction) game” (Q1), and "no core relationship" (Q2). The consultant body of governments-the 36 Research Committee showed essential criteria or guidelines, but the core relationship was not able to be made (Q3).

In Case II, the relationship improved moderately and the rules game established (Q1). However, there were lacks of reputation, trust, and reciprocity, and these made the vulnerable relationship (Q2). The residents had the higher desire and interest to change policy from the default position (a1); however, they shifted (to b1). The authority's stable attitude was to maintain conventional project procedure (b2); however, they compromised (to b1). Therefore, both stakeholder's choice was not stable. ID was accomplished, but both positions were no stable and fragile (Q3). 
In Case III, after repeated interactions, the residents' position changed (from a1 to b1). The factor that made residents change was the documentation of "rules" through repeated reliable negotiations, and the rules game established (Q1). Each stakeholder had endeavored to maintain "reputation, trust, and reciprocity" from the beginning to the end (Q2). The governments had a stable attitude, to reflect the residents' opinion of the construction process. They could change the conventional city planning process. They already had the guidelines by the 36 Research Committee's submissions (the default position was b1). Opposite, the residents hoped to stop the roadwork. There was a chance that the residents might change their original positions (from b1 to a1). ID was established in the circumstances that the government's position was stable and the resident's organization's position was not stable (Q3).

\section{Summary: Interactions Beyond Conventional City Planning in Kotake-Mukaihara District, Tokyo}

Next, the author arranged and compared the policy issues generated by the government and the resident's interactions, and the policy outcomes (Q4).

We can find such as additional "original solutions" (as institutional solutions, and additional policy in city planning and execution procedure) in these public works (see Table 1).

Table 1

Transformation of the Policy Issue in Kotake-Mukaihara District (1970-1991)

\begin{tabular}{|c|c|c|}
\hline The policy issue & Case No. & Original solution type \\
\hline Democratic city planning procedure [institutional design] & Case I & $\square$ \\
\hline Civil engineering and compensation & Case II, Case III & \\
\hline $\begin{array}{l}\text { Detailed construction planning management [Partnership] } \\
\text { (management procedure making) }\end{array}$ & Case II, Case III & $\square(0)$ \\
\hline Environmental policy (Environmental Assess./Landscape) & (Case II) Case III & () \\
\hline Livable city planning (facilities) & Case III & () \\
\hline Post-railway construction [consultation continuation] ok. & Case II & $\square$ \\
\hline Post-road construction [consultation continuation] ok? & Case III & ( $\square)$ \\
\hline
\end{tabular}

Notes. Original solution (not conventional city Planning) included two types of solutions, as follows:

(1) Institutional solution: [ ], , and (2) Additional policy: (_), O.

Nevertheless, after these solutions were conducted, some residents' anxieties remained post- the service start. "ok.” connote it was solved (Case II ). “ok?” connote it was not solved (Case III).

(by Yamada, 2018, June, revised)

In other words, these solutions were not the same as conventional city planning, as we shall see below:

(1) Addition of democratic procedures;

(2) Addition of policies (The difference between Case II and Case III was significant).

In the railway works, the residents' livelihood, improvement of the local environment, and the decrease of construction damage were big concerns.

In the roadwork, facility design, the environmental impact assessment items were making, and environmental conservation, as the antipollution measure, etc., were added.

Moreover, as the additional explanation, we refer as follows:

First, in the roadwork, the pressure of assurance by the residents' was stronger than the former railway works. Also, second, the necessity of keeping reciprocity to maintain the local area post-construction was stronger, too.

In the above view of (difference of) constraints, the author concludes that the constraining forces were not 
the same in the MRT underground railway works' and the Road 36 roadworks'. In general, we may be able to point out that administrative planning to construct social infrastructure facilities has, as a typical policy, a strong binding force.

\section{Conclusions}

We concluded two crucial items, as follows:

\section{Regarding “Government”}

Policy constraints. The prefectural city planning was old, and the roadwork plan, established through a bureaucracy that constraint, may become stronger over time (The policy has been installed for many years the government since before WWII).

The Pierson's hypothesis, constraints become stronger over time is supported.

A trial by the former governor of Tokyo. The city planning procedure development, by the former governor of Tokyo, was a trial to challenge the constraints.

The will of the development became clear in form, through the setting up of a committee. These led to the formation of concrete guidelines as "the basic principle of road constructions", before the consultant body carried out investigations.

\section{Regarding "Partnership"}

The democratic governance. The part of the essential criteria was inherent in the latter public works by each stakeholder. Mostly, making the rules game seems that contributed to keeping repeated negotiation, simultaneously the establishment of some rules included the original guidelines.

In the trial of partnership era, between the Government of Tokyo and the 36 Residents' Committee endeavored to keep "reputation, trust, and reciprocity”. This situation looks like a lifeline of their institutional setting (repeated negotiation interaction)’s stability.

Following observation, we conclude that partnership (core relationship) practice was accomplished surely in the Case III than in Case II. (Q5)

Additional hypothetical configuration descriptions. "Documentation rule" in the rules making process might be the necessity. This process seems that made stronger the institutional resilience within the transparent and accountable game settings.

Also, to solve the bounds of the past social-political environment (Tsuji, 1972; Shinohara, 1972), setting the norms game or the rules game may become an effective way in general.

Progressing the logical connection between ID and Statement (game), and describing policy issue transformation, we shall show another paper.

\section{Acknowledgement}

This paper is based on a presentation of Yamada (2018, June) at the 1st International Workshops on Public Policy at the University of Pittsburgh, June 26-28, and we primarily focused on the technical parts. We thank to "T02W15-Towards an urban policy analysis: Linking urban politics and public policy” organizers, David Kaufmann, Mara Sidney, and then, Abigail Fisher W. and the other discussants very much.

\section{References}

Bready, H. E., Collier, D., \& Seawright, J. (2004). Source of leverage in causal influence: Toward an alternative view of 
methodology. In H. E. Bready and D. Collier (Eds.), Rethinking social inquiry: Diverse tools, shared standards (1st ed., pp. 229-266). Lanham, MD: Rowman \& Littlefield Publishers, Inc.

Evera, S. V. (1997/2009). Guide to methods for students of political science (Japanese translation: Seijigaku no Research Method, K. Noguchi and S. Watanabe, Trans.). Tokyo: Keisoshobo.

Mayer, M., \& Boudreau, J. A. (2012). Social movements in urban politics: Trends in research and practice. In K. Mossberger, S. E. Clarke, and P. John (Eds.), The Oxford handbook of urban politics (pp. 273-291). New York, N.Y.: Oxford University Press.

McGinnis, M. D. (Ed.). (1999). Introduction. In Polycentricity and local public economies (pp.1-27). Michigan, MI: University of Michigan Press.

Munck, G. L. (2004/2008). Tools for qualitative research (Japanese translation: Teiseiteki Kenkyu no Bunseki Dogu). In H. E. Bready, and D. Collier (Eds.), Rethinking social inquiry: Diverse tools, shared standards (Japanese translation: Shakai Kagaku no Houhou Ronso: Tayo na Bunseki Dogu to Kyotuu no Kijun, Y. Izumikawa and A. Miyashita, Trans., pp. 119-135). Tokyo: Keisoshobo.

Ostrom, E. (2005). Understanding institutional diversity. Princeton, NJ: Princeton University Press.

Ostrom, E. (2007). Collective action theory. In C. Boix and S. C. Stoles (Eds.), The Oxford handbook of comparative politics (pp. 186-208). Oxford, UK: Oxford University Press.

Pierre, J., \& Peters, B. G. (2012). Urban governance. In K. Mossberger, S. E. Clarke, and P. John (Eds.), The Oxford handbook of urban politics (pp. 71-86). New York, N.Y.: Oxford University Press.

Pierson, P. (2004). Politics in Time: History, Institutions and social analysis. Princeton, NJ: Princeton University Press.

Shinohara, H. (1972). Gendai Seiji to Toshi (Modern politics and City). In M. Ito, H. Shinohara, K. Matsushita, and K.Miyamoto (Eds.), Gendai Toshi Seisaku I: Tosih seisaku no kiso. iwanami koza (Modern Urban Policy I: The basics of urban policy. Lectures of Iwanami, pp. 101-123). Tokyo: Iwanami Shoten.

Tokyo Metropolitan Government Bureau of Citizens and Cultural Affairs. (1982). Hosha 36Go Doro mondai kankei shiryo shu (The document collections related to Road 36 Issue). Tokyo: Author.

Tsuji, K. (1972). Nihon ni Okeru Jichi (Local autonomy in Japan). In M. Ito, H. Shinohara, K. Matsushita, and K.Miyamoto (Eds.), Gendai Toshi Seisaku I: Toshi seisaku no kiso. iwanami koza (Modern Urban Policy I: The basics of urban policy. Lectures of Iwanami, pp. 124-150). Tokyo: Iwanami Shoten.

Wagenaar, H., \& Cook, S. D. N. (2003). Understanding policy practices: action, dialectic and deliberation in policy analysis. In M. A. Hajer and H. Wagenaar (Eds.), Deliberative policy analysis: Understanding governance in the network society (pp. 139-171). Cambridge, UK: Cambridge University Press.

Yamada, C. I. (2018, June). A comparative history partnership by historical institutional theory view-3 experiments beyond conventional city planning 1970-1991 in Kotake-Mukaihara District, Tokyo. Paper presented at The 1st International Workshops on Public Policy of the International Public Policy Association, Pittsburgh University, Pittsburgh, PA. 


\section{Appendix}

List of materials in use-The document collections relating to Road 36 Issue: chronological order

1. Documents: formulated written demands, returns, and agreements, etc.

a. MRT underground railway No.8, No.13, Seibu-Yurakucho Line

- "Renmei Shuisho" dated 1976/09/16 (The prospectus). (The 8.13 Residents' Committee)

- Memorandum dated 1977/03/18. (The 8.13 Residents' Committee, TRTA's planning division, and the construction office land division was signed)

- The cooperation agreement dated 1978/07/07. (TRTA and the 8.13 Residents' committee signed)

- Written request dated 1978/10/24: Regarding the No.8 underground railway works. (The 8.13 Residents' Committee: to the Governor of Tokyo, Ryokichi Minobe)

- Certificate dated 1979/03/06. (signed by all stakeholders (TRTA official, the residents \& three construction companies)

b. Road 36

- Requisition dated 1980/10/27. (The 36 Residents’ Committee)

- Document for a press release, dated 1980/11/15. (The $35 \cdot 36$ Residents Meetings, liaisons)

- Official written response dated 1980/11/15. (The Governor of Tokyo, Shunichi Suzuki)

- Firm commitment dated 1981/07/03. (The Government of Tokyo (Bureau of Construction) and the 36 Residents' Committee signed)

- Mutual agreement dated 1981/09/29. (The Government of Tokyo and the 36 Residents' Committee)

- Agreement dated 1987/03/20. (The Government of Tokyo and the 36 Residents' Committee)

- Mutual agreement dated 1987/03/20. (The Government of Tokyo and the 36 Residents' Committee)

2. Newsletters

(Case I)

1973-1975

Machi to Doro (City and Road), No.1 (1973/09/15)-No.11 (1975/09/20).

Tokyo: Tokyo Metropolitan Government Tomin-Shitu (Citizen’s Room).

1970-1983

Oshirase (Information), No.1 (1970/07/28)-No.19 (1976/07/02), and No.19 (1983/04). Tokyo: The 35 • 36 Residents’ Meeting. (Case II)

1976-1985

Kaiho (The Measures' information), No.1 (1976/09/03)-N0.53 (1985/01/08). Tokyo: The committee for Quality Control of The MRT underground railway No.8 and No.13 construction (The 8.13 Residents' Committee).

(Case III)

1980-1987

36 Renmei News (The Committee’s News), No.1 (1980/11/04)-No.20 (1987/06/15). Tokyo: The Committee for Quality Control of Road 36 construction (The 36 Residents' Committee). 